\title{
Perkembangan Agribisnis Teh Selama Pandemi Covid - 19 di PTPN VIII Kebun Kertamanah, Pangalengan, Jawa Barat
}

\author{
Tea Agribusiness Development During the Covid - 19 Pandemic in PTPN VIII \\ Kertamanah Plantation, Pangalengan, West Java
}

\author{
Diva Maurizky dan Ernah \\ Program Studi Agribisnis, Departemen Sosial Ekonomi Pertanian, \\ Fakultas Pertanian, Universitas Padjadjaran, Sumedang \\ *Kontak penulis: diva17002@mail.unpad.ac.id ; ernah@unpad.ac.id
}

\begin{abstract}
PTPN VIII Kertamanah PTPN Plantation is a country's company under the Ministry of State-Owned Enterprises that engaged in the production of tea which has a good reputation in West Java. However, national's tea production was tending to decrease in these past months and even get worsen because of the Covid - 19 pandemics which also has an impact on the plantation sector. This study aims to determine the tea agribusiness performance, internal and external factors in the company, and decide the viable tea agribusiness development strategies. This research uses descriptive-qualitative design and study case research technique. In needs to explaining the tea agribusiness performance is done descriptively, meanwhile for finding the right developing strategy there needs to be a matrix analysis of IFAS, EFAS, $I E$, and SWOT. Based on the descriptive data analysis, the production input procurement subsystem supports the production / cultivation and processing subsystem. Furthermore, those two subsystems support the running of the marketing subsystem. The smooth activites of all subsystems are supported by several supporting institutuions. The SWOT analysis resulted nine alternative strategies as like: (1) Mantaining performance and quality, (2) Opening job labor, (3) Making an inovation, (4) Maximazing the use of technology, (5) Maximazing company's assets, (6) Work together with government and counseller, (7) Making a more detailed plan, (8) Take advantage of the superior factory program, and (9) Increasing promotion as long as the interesting education.
\end{abstract}

Keywords: Agribusiness Development Strategy; SWOT; Tea.

\begin{abstract}
Abstrak
PTPN VIII Kebun Kertamanah merupakan perusahaan negara yang berada di bawah naungan Kementerian BUMN yang bergerak pada produksi tanaman teh yang memiliki reputasi yang baik di Jawa Barat. Akan tetapi hasil produksi teh nasional cenderung menurun beberapa tahun terakhir serta diperkeruh dengan adanya pandemi Covid - 19 yang turut berdampak pada sektor perkebunan. Penelitian ini bertujuan untuk mengetahui keragaan agribisnis teh, mengetahui faktor internal dan eksternal pada perusahaan, serta menentukan strategi pengembangan agribisnis teh yang tepat. Desain penelitian ini adalah kualitatif dengan teknik penelitian studi kasus. Metode pengumpulan data yang digunakan ialah wawancara, observasi, dan studi literatur. Dalam menjelaskan keragaan agribisnis dilakukan secara deskriptif, sedangkan dalam menentukan strategi pengembangan yang tepat, digunakan analisis matriks IFAS, EFAS, IE, dan SWOT. Berdasarkan penguraian data secara deskriptif, subsistem pengadaan input produksi mendukung berjalannya subsistem produksi / budidaya dan subsistem pengolahan, selanjutnya kedua subsistem tersebut mendukung berjalannya subsistem pemasaran. Kelancaran kegiatan seluruh subsistem ditunjang oleh beberapa lembaga penunjang. Berdasarkan hasil analisis SWOT diperoleh sembilan alternatif strategi sebagai berikut : (1) Mempertahankan kinerja dan kualitas, (2) Membuka lapangan kerja, (3) Melakukan inovasi, (4) Memaksimalkan penggunaan teknologi, (5) Memaksimalkan aset perusahaan, (6) Bekerjasama dengan aparatur pemerintahan dan lembaga penyuluh, (7) Melakukan
\end{abstract}


perencanaan dengan lebih mendetail, (8) Memanfaatkan program pabrik unggulan, dan (9) Meningkatkan promosi sekaligus edukasi yang menarik.

Kata Kunci : Strategi Pengembangan Agribisnis; SWOT; Teh.

\section{Pendahuluan}

Teh (Camellia sinensis) merupakan komoditas tanaman perkebunan dan produk minuman dengan konsumsi tertinggi di dunia. Tingginya konsumsi teh dunia mendorong pelaku industri teh untuk terus menghasilkan produk teh dengan kualitas terbaik guna memenuhi permintaan pasar. Maka dari itu perkebunan dan pabrik teh tersebar hampir di seluruh dunia termasuk Indonesia. Di Indonesia tanaman perkebunan merupakan subsektor dengan kontribusi terbesar terhadap peningkatan pendapatan nasional dan devisa negara. Hal tersebut dapat dilihat dari produk domestik bruto (PDB) sektor pertanian, tanaman perkebunan memberikan kontribusi tertinggi yakni sebesar 39,54\%. Perkembangan PDB tanaman perkebunan terus mengalami peningkatan yang menunjukkan tingginya kontribusi tanaman perkebunan terhadap perekonomian nasional. Perkembangan PDB tanaman perkebunan selama lima tahun terakhir ditunjukkan pada Gambar 1.

\section{Gambar 1. PDB Tanaman Perkebunan}

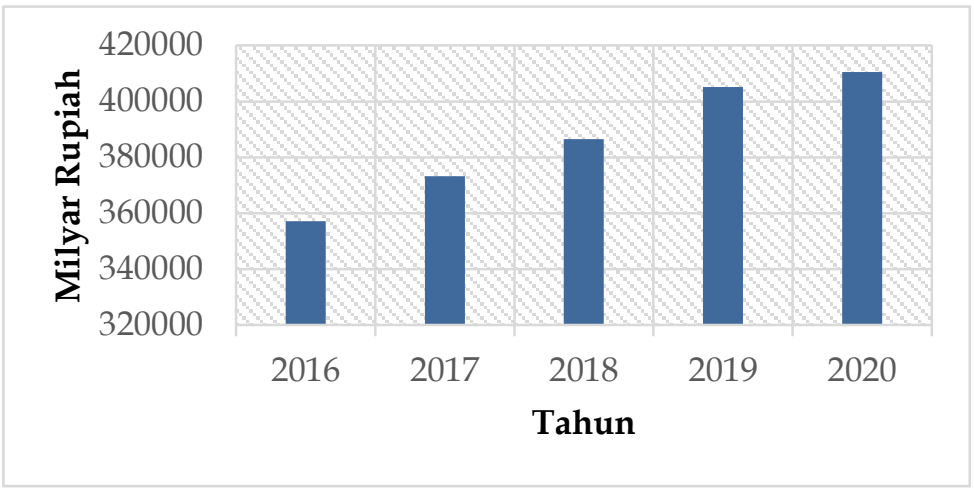

Sumber : BPS, 2021

Pemerintah menetapkan beberapa tanaman perkebunan sebagai komoditas unggulan nasional, salah satunya adalah teh. Teh Indonesia pun terkenal akan kandungan katekin tertinggi di dunia yang dapat menjadi peluang guna meningkatkan eksistensinya jika terus dikembangkan. Dari sisi produksi perkembangannya cukup berfluktuatif dan didominasi oleh perkebunan besar baik yang dimiliki oleh negara maupun swasta. Ditingkat dunia pada tahun 2020 Indonesia menempati posisi delapan sebagai negara dengan produksi tertinggi yakni 148.100 ton. Produksi nasional tertinggi diraih pada tahun 2017 dengan Jawa Barat sebagai provinsi dengan kontributor tertinggi, yakni sebanyak 57.921 ton atau 63,01\% dari total produksi perkebunan besar di Indonesia. Sebaran daerah yang berkontribusi terhadap produksi teh di Jawa Barat ditunjukkan pada Tabel 1. 
Tabel 1.

Kontribusi Produksi Teh di Jawa Barat

\begin{tabular}{|c|c|c|}
\hline No. & Kabupaten & Besar Kontribusi \\
\hline 1. & Kabupaten Bandung & $34,04 \%$ \\
\hline 2. & Kabupaten Cianjur & $19,46 \%$ \\
\hline 3. & Kabupaten Tasikmalaya & $13,54 \%$ \\
\hline 4. & Kabupaten Garut & $9,48 \%$ \\
\hline 5. & Sukabumi & $6,27 \%$ \\
\hline 6. & Lainnya & $17,20 \%$ \\
\hline
\end{tabular}

Sumber : Kementerian Pertanian, 2016

Berdasarkan Tabel 1 terlihat bahwa Kabupaten Bandung mendominasi produksi sebesar 34,04\% dari keseluruhan produksi di Jawa Barat. Perkebunan teh yang berada di Kabupaten Bandung mayoritas dimiliki oleh perkebunan besar milik negara yakni PT. Perkebunan Nusantara VIII, perusahaan dengan perkebunan teh terbesar dan terluas di Indonesia. Diantara 23 perkebunan yang dimiliki oleh PTPN VIII, Kebun Kertamanah adalah salah satu kebun yang terletak di Kecamatan Pangalengan, Kabupaten Bandung. Kebun Kertamanah memiliki lahan seluas 2.885,12 Ha dengan pabrik yang mengolah teh secara orthodox. Produksinya cukup berfluktuatif dengan produksi tertinggi diraih pada tahun 2017 sebesar 2.153 ton dan didominasi untuk pasar ekspor dengan berbagai negara tujuan.

Kendati demikian menurut Rohanti, seorang pakar teh dari PT. Riset Perkebunan Nusantara (RPN), industri teh nasional kian meredup yang disebabkan oleh berbagai faktor salah satunya dengan melemahnya produksi teh nasional. Menurut penelitian (Ratih et al., 2012), penurunan produksi terjadi sebesar 0,8\% per tahun. Keadaan diperburuk dengan adanya pandemi Covid - 19 yang mulai terjadi di Indonesia pada bulan Maret 2020. Adanya pandemi cukup berdampak bagi subsektor perkebunan yang disebabkan karena aktivitas panen yang tidak dapat dilakukan secara maksimal serta adanya pembatasan sosial yang berdampak pada penurunan produksi. Selain itu pasar internasional pun terganggu karena adanya kebijakan lockdown oleh beberapa negara tujuan ekspor.

Berdasarkan pertimbangan tersebut maka dilakukan penelitian mengenai perkembangan agribsinis teh selama pandemi Covid - 19 yang ditinjau dari sisi keragaan agribisnis melalui pendekatan sistem agribisnis. Menurut (Gumbira-Sa'id \& Intan, 2001), tiap subsistem dalam sistem agribisnis saling berhubungan sehingga jika hubungan tersebut dapat berjalan dengan baik maka agribisnis sebagai sebuah sistem pun dapat berjalan dengan baik. Dilakukan juga penelitian untuk mengetahui faktor lingkungan internal maupun eksternal perusahaan. Menurut (Silaban, 2020), analisis lingkungan merupakan merupakan proses yang bertujuan untuk merencanakan strategi guna menentukan kekuatan, kelemahan, peluang, dan ancaman yang dimiliki perusahaan. Penelitian ini bertujuan untuk mengetahui keragaan agribisnis teh selama pandemi Covid - 19 serta menentukan strategi pengembangan yang tepat berdasarkan lingkungan internal dan eksternal perusahaan. 


\section{Metode Penelitian}

Penelitian ini dilakukan di Kebun Kertamanah, Kecamatan Pangalengan, Jawa Barat selama masa pandemi Covid - 19, akhir 2020 sampai awal 2021. Objek penelitian ini ialah keragaan agribisnis teh selama pandemi Covid - 19 serta faktor internal dan ekstenal perusahaan. Desain penelitian yang digunakan ialah desain kualitatif dengan teknik studi kasus (case study). Desain penelitian kualitatif digunakan untuk mendeskripsikan dan menggambarkan suatu fenomena atau kedaan dengan cara menganalisis data yang diperoleh tanpa bermaksud untuk membuat kesimpulan secara umum atau generalisasi (Sugiyono, 2015). Kasus yang diteliti dengan teknik penelitian studi kasus dibatasi oleh waktu dan kegiatan tertentu dimana para peneliti memperoleh data menggunakan berbagai macam teknik pengumpulan data selama periode waktu tertentu (Creswell, 2014). Sumber data terdiri dari data primer yang diperoleh melalui wawancara dengan enam orang informan dan melalui observasi pada saat kegiatan magang. Data sekunder diperoleh dari data perusahaan serta melalui berbagai studi literatur yang mendukung data primer.

Analisis deskriptif digunakan untuk menggambarkan keragaan agribisnis teh di Kebun Kertamanah. Analisis matriks IFAS (Internal Factors Analysis Summary) digunakan untuk merumuskan faktor - faktor strategis internal yang ditinjau dari sisi sumberdaya, manajemen, pemasaran, keuangan / akuntansi, produksi / operasi, serta penelitian dan pengembangan guna mengetahui kekuatan dan kelemahan perusahaan. Analisis Matriks EFAS (External Factors Analysis Summary) digunakan untuk merumuskan faktor - faktor strategis eksternal yang ditinjau dari sisi ekonomi, sosial, politik, teknologi, dan kompetitif guna mengetahui peluang dan ancaman perusahaan. Analisis Matriks IE (Internal - External) digunakan untuk menggabungkan total skor yang diperoleh dari matriks IFAS dan EFAS guna mengetahui implikasi strategi yang tepat bagi perusahaan sesuai dengan posisinya. Analisis SWOT digunakan untuk menentukan strategi yang tepat bagi perusahaan dengan memaksimalkan kekuatan (strengths) dan peluang (opportunities) serta pada waktu yang bersamaan dapat mengurangi kelemahan (weakness) serta ancaman (threats) yang dihadapi perusahaan (Rangkuti, 1997).

\section{Hasil dan Pembahasan}

\section{Keragaan Agribisnis Teh Selama Pandemi Covid - 19 Subsistem Pengadaan Input Produksi}

Subsistem pengadaan input produksi di Kebun Kertamanah secara garis besar kegiatannya meliputi perencanaan, pengelolaan, dan pengadaan sarana produksi, teknologi, dan sumberdaya pertanian. Hal ini sejalan dengan penelitian yang dilakukan oleh (Choiri \& Sunartomo, 2008), yang menyatakan bahwa input produksi yang optimal merupakan salah satu faktor dalam keberhasilan berusahatani. Terdapat beberapa perencanaan yang dibuat untuk 105 blok kebun yang ada di Kebun Kertamanah diantaranya RJP (Rencana Jangka Panjang) untuk periode lima tahun, RKAP (Rencana Keuangan Anggaran Perusahaan) untuk periode satu tahun, PKB (Proyeksi Keuangan Bergulir) untuk periode tiga bulan, dan RKB (Rencana Kerja dan Anggaran Biaya) untuk periode satu bulan. Dalam pelaksanaannya Kebun Kertamanah berkoordinasi dengan kantor direksi PTPN VIII agar pengadaan dapat dilakukan tepat waktu, tepat 
jumlah, dan tepat jenis. Beberapa sarana dan prasarana produksi teh di Kebun Kertamanah ditunjukkan pada Tabel 2.

Tabel 2.

Sarana dan Prasarana Produksi Teh di Kebun Kertamanah

\begin{tabular}{|c|c|l|}
\hline No. & Kegiatan & \multicolumn{1}{|c|}{ Sarana dan Prasarana } \\
\hline 1. & Persemaian & $\begin{array}{l}\text { Bibit diperoleh dari PPTK Gambung yang terdiri dari } \\
\text { Gambung 3, 7,9, 11 dengan jenis TRI 2024 dan TRI 2025 }\end{array}$ \\
\hline 2. & Pemeliharaan & $\begin{array}{l}\text { Penyiangan : kored / parang / gacok, knapsack sprayer, } \\
\text { herbisida sistemik } \\
\text { Pemupukan : Kimia (N, P, K, Zn, ZnSO4) \& Organik } \\
\text { (kotoran hewan) } \\
\text { Pengendalian hama dan penyakit : larutan fungisida, mist } \\
\text { blower, power sprayer, sanchin, hand sprayer } \\
\text { Pemangkasan : Gaet, mesin pangkas } \\
\text { Perataan bidang petik : Skipping } \\
\text { Pembuatan dawungan : mesin dawung }\end{array}$ \\
\hline 3. & Pemetikan & $\begin{array}{l}\text { Pemetikan dengan gunting : Gunting petik, waring sack, } \\
\text { junak, terpal, tenda } \\
\text { Pemetikan dengan mesin : mesin petik, collecting bag, } \\
\text { waring sack } \\
\text { Perlengkapan penimbangan : Timbangan salter, jangka, } \\
\text { mobil angkut, tataban (besi pembatas) }\end{array}$ \\
\hline 4. & Pengolahan & $\begin{array}{l}\text { Wood pellet untuk bahan bakar drier } \\
\text { Mesin - mesin pengolahan }\end{array}$ \\
\hline
\end{tabular}

Sumber : PTPN VIII Kebun Kertamanah, 2021

Menurut (Karmini, 2020), bahan baku atau input produksi adalah barang atau jasa yang menunjang berjalannya kegiatan produksi, dimana perkembangannya mengikuti perkembangan yang ada pada proses produksi. Maka dari itu subsistem pengadaan input produksi di Kebun Kertamanah sudah berjalan dengan baik karena telah mendukung kelancaran kegiatan pada subsistem produksi / budidaya hingga subsistem pengolahan. Pandemi covid - 19 tidak memberikan pengaruh yang berarti karena tidak adanya perubahan / penyesuaian kegiatan antara sebelum dan selama adanya pandemi Covid - 19 di Kebun Kertamanah.

\section{Subsistem Produksi / Budidaya}

Kegiatan utama pada subsistem ini ialah menghasilkan pucuk teh sebagai bahan baku bagi subsistem pengolahan. Berdasarkan Standard Operational Procedure (SOP) yang berlaku, tahapan kegiatan produksi / budidaya teh di Kebun Kertamanah terdiri dari pembuatan persemaian, pengelolaan TTI (Tanaman Tahun Ini), pemeliharaan TBM (Tanaman Belum Menghasilkan), pemeliharaan TM (Tanaman Menghasilkan), dan pemetikan.

Bibit persemaian yang digunakan oleh Kebun Kertamanah saat ini berasal dari balai Pusat Penelitian Teh dan Kina (PPTK) Gambung, dimana jenis tanaman teh yang ditanam pada tiap blok kebun dibedakan menjadi jenis seedling dan klonal. Kegiatan 
pada pengelolaan TTI ialah penanaman pada areal baru (new planting) maupun pada areal peremajaan (replanting) yang dilakukan pada tahun berjalan, agar kegiatan penanaman dapat berjalan dengan baik dan menghasilkan tanaman teh dengan produktivitas tinggi. Pemeliharaan TBM bertujuan untuk mempersiapkan tanaman agar memiliki kondisi yang sehat dengan potensi yang tinggi, kegiatannya terdiri dari penyiangan, pembuatan rorak, penyulaman, pemupukan, pembentukan frame, serta penanaman pohon pelindung. Pemeliharaan TM dibagi menjadi enam sub pengerjaan atau biasa disebut rekening, yakni rekening pemeliharaan jalan, rekening pengendalian gulma, rekening pengendalian hama dan penyakit, rekening pemupukan, rekening pangkasan, serta pekerjaan lain - lain. Kegiatan pemetikan dilakukan ketika tanaman sudah memasuki masa panen. Tiap blok kebun memiliki masa panen yang berbeda bergantung pada jenis tanaman, teknik pemetikan, dan gilir petik. Tanaman klonal yang dipanen menggunakan mesin memiliki gilir petik kurang lebih 47 hari sedangkan untuk jenis seedling kurang lebih 76 - 78 hari. Untuk panen dengan menggunakan gunting gilir petik berkisar pada 30 - 35 hari. Dalam sekali kegiatan panen pemetik ditargetkan untuk mencapai minimal $45 \mathrm{~kg}$ pucuk basah/hari/orang serta pucuk teh harus memenuhi syarat olah analisa pucuk medium antara 60 - 70\%. Perkembangan produktivitas teh di Kebun Kertamanah ditunjukkan pada Tabel 3.

Tabel 3.

Produktivitas Teh Kebun Kertamanah

\begin{tabular}{|c|c|c|c|c|c|c|}
\hline \multirow{2}{*}{ Bulan } & \multicolumn{6}{|c|}{ Tahun (Kg/Ha) } \\
\hline & 2016 & 2017 & 2018 & 2019 & 2020 & 2021 \\
\hline Januari & 181 & 180 & 188 & 224 & 235 & \\
\hline Februari & 115 & 168 & 129 & 144 & 168 & \\
\hline Maret & 168 & 98 & 117 & 203 & 200 & P \\
\hline April & 183 & 169 & 148 & 209 & 214 & $\mathbf{R}$ \\
\hline Mei & 154 & 202 & 171 & 197 & 194 & $\mathrm{O}$ \\
\hline Juni & 165 & 159 & 142 & 179 & 215 & $\mathbf{Y}$ \\
\hline Juli & 134 & 200 & 158 & 190 & 204 & E \\
\hline Agustus & 160 & 163 & 108 & 91 & 169 & $\mathbf{K}$ \\
\hline September & 165 & 124 & 49 & 74 & 136 & $S$ \\
\hline Oktober & 179 & 175 & 41 & 66 & 150 & I \\
\hline November & 165 & 193 & 58 & 38 & 156 & \\
\hline Desember & 179 & 199 & 186 & 158 & 204 & \\
\hline Jumlah & 1948 & 2040 & 1496 & 1773 & 2245 & 2297 \\
\hline
\end{tabular}

Sumber : Realisasi Produksi Kering dan Protas Kebun Kertamanah, 2021

Berdasarkan Tabel 3 terlihat bahwa tingginya produksi terjadi pada tahun 2020 yang disebabkan oleh kondisi tanaman yang semakin sehat. Kondisi tanaman yang sehat selanjutnya akan menghasilkan produksi dengan kualitas yang semakin baik pula, maka dari itu subsistem produksi dan pengolahan saling berikatan antara satu dan yang lain. Keadaan tersebut sejalan dengan penelitian pada komoditas kakao yang dilakukan oleh (Suoth et al., 2019) yang menyatakan bahwa, agriindustri hulu menyediakan input bagi proses produksi pada agroproduksi berupa budidaya tanaman kakao dan agriproduksi menyediakan input bagi agroindustri hilir. Kondisi pandemi 
Covid - 19 tidak memberikan pengaruh pada kegiatan produksi / budidaya karena tidak ada perubahan yang terjadi dibandingkan sebelum adanya pandemi Covid - 19 . Hal tersebut didukung dengan proyeksi produktivitas pada tahun 2021 yang turut mengalami kenaikan.

\section{Subsistem Pengolahan}

Pengolahan teh yang dilakukan di pabrik Kebun Kertamanah dilakukan dengan teknik orthodox. Tahapan kegiatan pengolahan dimulai dari pengangkutan dan penerimaan bahan baku, pelayuan, penggilingan, oksidasi enzimatis, pengeringan, sortasi, pengepakan dan penyimpanan, serta pengangkutan. Pabrik teh di Kebun Kertamanah saat ini hanya mampu mengolah pucuk basah 25 ton/hari sehingga pucuk berlebih dari lapangan harus dikirimkan dan diolah oleh pihak lain. Meskipun demikian, produk teh yang dihasilkan oleh Kebun Kertamanah didominasi oleh penjualan untuk pasar ekspor dengan berbagai grade. Beberapa grade yang menjadi unggulan diantaranya BOPF, BOP, BP, DUST, dan FANN II.

Berdasarkan uraian di atas diketahui bahwa hasil pengolahan yang baik akan berdampak pada kegiatan pemasaran yang baik pula, dimana pengolahan dapat memberikan hasil yang maksimal jika dibekali oleh bahan baku pucuk yang baik pula. Keadaan tersebut sejalan dengan penelitian yang dilaksanakan oleh (Arfah, 2019), dimana pengolahan biji kakao didukung oleh kegiatan on farm yang dilakukan oleh para petani kakao guna selanjutnya dipasarkan baik melalui industri besar maupun kecil (rakyat). Secara garis besar keadaan pandemi Covid - 19 tidak memberikan pengaruh berarti karena kegiatan masih berjalan sesuai prosedur sebagaimana yang terjadi sebelum adanya pandemi. Meskipun demikian, hambatan terjadi pada awal pandemi karena adanya kebijakan Pembatasan Sosial Berskala Besar (PSBB) yang menghambat pengiriman pucuk berlebih ke pihak ketiga.

\section{Subsistem Pemasaran}

Kegiatan pemasaran produk hasil olahan pabrik Kebun Kertamanah tidak dipasarkan secara mandiri melainkan dikelola oleh holdings PTPN III, sehingga Kebun Kertamanah dan PTPN VIII hanya bergerak di sisi logistik penyedia dan pengiriman barangnya saja. Hal tersebut sesuai dengan teori yang dikemukakan oleh (Rahim \& Hastuti, 2005), dimana untuk perkebunan besar pemasaran dilakukan oleh KPB (Kantor Pemasaran Bersama) yang selanjutnya akan menjadi pihak yang melakukan transaksi dengan pihak eksportir atau pembeli. Hasil produksi Kebun Kertamanah umumnya dipasarkan melalui dua cara, melalui auction yang dilakukan oleh PT. KPBN (Kharisma Pemasaran Bersama Nusantara) dan melalui private offer oleh pihak pembeli kepada holdings PTPN III. Kebun Kertamanah rutin mengirimkan sample teh tiap minggunya untuk diikut sertakan dalam auction, sedangkan untuk private offer saat ini salah satu perusahaan yang sedang berada dalam kontrak penjualan teh dengan PTPN VIII termasuk Kebun Kertamanah ialah Unilever. Proses penentuan harga untuk private offer umumnya ditentukan berdasarkan kontrak (Ratih et al., 2012), sedangkan untuk auction harganya cenderung berfluktuatif dengan harga terbaru berada pada kisaran $\$ 1,4 / \mathrm{kg}$.

Berdasarkan uraian di atas diketahui bahwa pemasaran yang baik ditunjang oleh hasil produksi yang baik pula sehingga disinilah adanya hubungan yang erat antara subsistem pengolahan dengan pemasaran. Pemasaran merupakan subsistem yang 
paling terdampak dengan adanya pandemi Covid - 19, hal ini disebabkan oleh terhambatnya logistik pengiriman barang ke beberapa negara tujuan karena adanya kebijakan lockdown.

\section{Lembaga Penunjang}

Lembaga penunjang berperan untuk mendukung kelancaran berjalannya sistem agribisnis beserta subsistem yang ada didalamnya. Lembaga pemerintahan yang sering berhubungan dengan Kebun Kertamanah ialah desa dan kecamatan, terkait kelancaran kegiatan kebun dan penanganan atas gangguan di lapangan. Lembaga pemerintahan lain yang turut terlibat ialah Kementerian BUMN dan Dewan Teh Indonesia (DTI). Lembaga penyedia tenaga kerja salah satunya PT. Sarana Lima Prakasa, sebagai penyedia tenaga kerja khususnya karyawan lepas untuk ditempatkan di berbagai subsistem yang ada di Kebun Kertamanah. Lembaga sertifikasi terdiri dari dua sertifikasi nasional yakni halal dan K3 (Keselamatan dan Kesehatan Kerja) serta dua sertifikasi internasional yakni Rainforest Alliance (RA) dan International Organization for Standarization (ISO). Keempat sertifikasi tersebut diajukan dan diurus oleh Kebun Kertamanah dengan masa berlaku selama lima tahun, diadakan pula pemantauan sertifikasi secara rutin tiap tahunnya. Hal ini sejalan dengan penelitian yang dilakukan oleh (Awaliyah, 2018), yang menyatakan bahwa terlindunginya produk oleh hak paten ataupun sertifikasi dapat memberikan nilai lebih ketika dipasarkan ke luar negeri. PPTK Gambung sebagai lembaga penelitian dan pengembangan, dimana perannya sebagai standar acuan dalam kegiatan budidaya teh di Kebun Kertamanah. Lembaga pemasaran ialah PT. KPBN yang bertanggung jawab atas pemasaran hasil produk yang dihasilkan oleh Kebun Kertamanah. Terdapat pula lembaga nasional maupun internasional yang mendukung ketersediaan data dan informasi terkait teh yakni Asosiasi Teh Indonesia dan International Tea Committee.

Seluruh subsistem agribisnis teh di Kebun Kertamanah sudah saling berkaitan antara subsistem yang satu dengan subsistem lainnya disertai beberapa lembaga penunjang yang mendukung kelancaran kegiatan pada tiap subsistem. Keragaan agribisnis teh di Kebun Kertamanah secara singkat ditunjukkan pada Gambar 2.

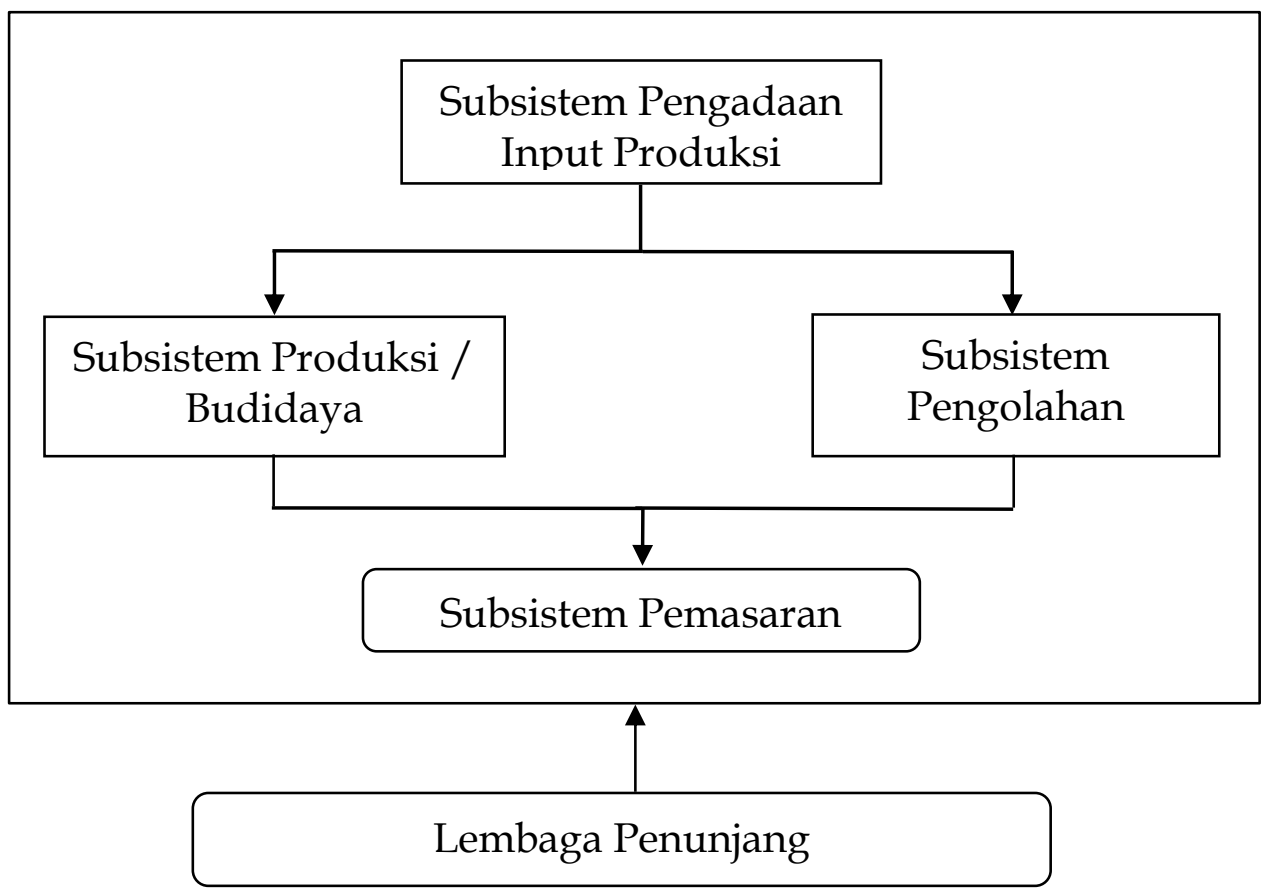

Gambar 2. Bagan Keragaan Agribisnis Teh di Kebun Kertamanah 
Subsistem pengadaan input produksi mendukung berjannya subsistem produksi / budidaya dan pengolahan, dimana kegiatannya dilakukan sendiri oleh pihak Kebun Kertamanah. Subsistem pengolahan dan produksi / budidaya mempengaruhi kegiatan pada subsistem pemasaran yang dikelola oleh holdings PTPN III. Secara garis besar adanya pandemi Covid - 19 tidak memberikan pengaruh besar terhadap kegiatan subsistem di Kebun Kertamanah, namun subsistem yang paling terdampak ialah subsistem pemasaran.

\section{Analisis Matriks IFAS}

Berdasarkan analisis matriks IFAS pada Tabel 4, dapat diketahui bahwa faktor "Areal Yang Luas Dengan Kondisi Tanaman Yang Sehat" merupakan kekuatan utama bagi perusahaan dengan skor 0.233. Faktor "Masih Adanya Hasil Produksi Yang Mengendap" merupakan kelemahan utama bagi perusahaan dengan skor 0.115. Secara keseluruhan total skor pada Analisis Matriks IFAS ialah 2.609, hal ini menunjukkan bahwa Kebun Kertamanah dianggap mampu memanfaatkan kekuatan perusahaan guna mengatasi kelemahannya secara optimal.

Tabel 4.

Analisis Matriks IFAS Teh Kebun Kertamanah

\begin{tabular}{|c|c|c|c|c|}
\hline No. & Faktor Strategi Internal & $\begin{array}{c}\text { Rata - } \\
\text { Rata } \\
\text { Peringkat }\end{array}$ & $\begin{array}{c}\text { Rata - } \\
\text { Rata } \\
\text { Bobot } \\
\end{array}$ & $\begin{array}{l}\text { Skor } \\
\text { Total }\end{array}$ \\
\hline \multicolumn{5}{|c|}{ Kekuatan } \\
\hline A & $\begin{array}{l}\text { Areal yang luas dengan kondisi tanaman yang } \\
\text { sehat }\end{array}$ & 3.50 & 0.067 & 0.233 \\
\hline B & $\begin{array}{l}\text { Kondisi agroklimat yang mendukung di areal } \\
\text { perkebunan }\end{array}$ & 3.67 & 0.059 & 0.217 \\
\hline $\mathrm{C}$ & Produktivitas tanaman yang terus meningkat & 3.33 & 0.053 & 0.177 \\
\hline $\mathrm{D}$ & $\begin{array}{l}\text { Sumberdaya manusia yang berpengalaman dan } \\
\text { terlatih }\end{array}$ & 3.50 & 0.056 & 0.196 \\
\hline $\mathrm{E}$ & Kemampuan manajerial / operasional perusahaan & 3.67 & 0.046 & 0.170 \\
\hline $\mathrm{F}$ & $\begin{array}{l}\text { Standar operasional serta alur kerja yang jelas dan } \\
\text { terstruktur }\end{array}$ & 3.67 & 0.044 & 0.161 \\
\hline G & Penelitian dan pengembangan secara berkala & 3.50 & 0.056 & 0.197 \\
\hline $\mathrm{H}$ & Relasi yang luas dan terjalin dengan baik & 3.33 & 0.064 & 0.213 \\
\hline I & $\begin{array}{l}\text { Menjadi bagian dari program pabrik unggulan } \\
\text { PTPN VIII }\end{array}$ & 3.67 & 0.054 & 0.199 \\
\hline \multicolumn{5}{|c|}{ KELEMAHAN } \\
\hline $\mathrm{J}$ & Kapasitas olah pabrik yang masih rendah & 1.50 & 0.081 & 0.121 \\
\hline K & Mutu produk yang belum konsisten & 1.83 & 0.087 & 0.159 \\
\hline $\mathrm{L}$ & Masih adanya hasil produksi yang mengendap & 1.33 & 0.087 & 0.115 \\
\hline $\mathrm{M}$ & $\begin{array}{l}\text { Pemasaran dan promosi yang masih belum } \\
\text { maksimal }\end{array}$ & 1.83 & 0.077 & 0.140 \\
\hline $\mathrm{N}$ & Akses jalan produksi yang kurang baik & 2.00 & 0.081 & 0.162 \\
\hline $\mathrm{O}$ & Sulitnya memperoleh mata air di lapangan & 1.67 & 0.088 & 0.147 \\
\hline \multicolumn{3}{|c|}{ Total } & 1.000 & 2.609 \\
\hline
\end{tabular}




\section{Analisis Matriks EFAS}

Berdasarkan analisis matriks IFAS pada Tabel 5, dapat diketahui bahwa faktor "Bagian Dari Perusahaan Milik Kementerian BUMN" merupakan peluang terbesar bagi perusahaan dengan skor 0.214. Faktor "Efek Pandemi Covid - 19 Yang Membatasi Pergerakan Pasar Internasional" merupakan ancaman terbesar bagi perusahaan dengan skor 0.115. Hal tersebut sejalan dengan penelitian yang dilakukan oleh (Prasetya et al., 2021) dimana lingkungan ekonomi merupakan faktor eksternal yang berpengaruh secara signifikan bagi usahatani padi. Secara keseluruhan total skor pada Analisis Matriks EFAS ialah 2.441, hal ini menunjukkan bahwa Kebun Kertamanah dianggap belum mampu merespon peluang - peluang yang tersedia guna mengatasi ancaman yang dapat mengganggu perkembangan usaha Kebun Kertamanah.

Tabel 5.

Analisis Matriks EFAS Teh Kebun Kertamanah

\begin{tabular}{|c|c|c|c|c|}
\hline No. & Faktor Strategi Eksternal & $\begin{array}{c}\text { Rata - } \\
\text { Rata } \\
\text { Peringkat }\end{array}$ & $\begin{array}{l}\text { Rata - } \\
\text { Rata } \\
\text { Bobot }\end{array}$ & $\begin{array}{l}\text { Skor } \\
\text { Total }\end{array}$ \\
\hline \multicolumn{5}{|c|}{ PELUANG } \\
\hline A & $\begin{array}{l}\text { Adanya agrowisata yang dapat membantu } \\
\text { menambah pendapatan perusahaan }\end{array}$ & 2.67 & 0.068 & 0.180 \\
\hline B & $\begin{array}{l}\text { Kandungan antioksidan pada teh yang bermanfaat } \\
\text { untuk kesehatan }\end{array}$ & 2.67 & 0.063 & 0.168 \\
\hline $\mathrm{C}$ & $\begin{array}{l}\text { Reputasi perusahaan sebagai salah satu kebun dan } \\
\text { pabrik teh terbaik di Jawa Barat }\end{array}$ & 2.83 & 0.064 & 0.183 \\
\hline $\mathrm{D}$ & Masyarakat disekitar lingkungan perusahaan & 2.50 & 0.067 & 0.168 \\
\hline $\mathrm{E}$ & Terjamin oleh sertifikasi nasional dan internasional & 3.00 & 0.061 & 0.184 \\
\hline $\mathrm{F}$ & Bagian dari perusahaan milik Kementerian BUMN & 3.00 & 0.071 & 0.214 \\
\hline G & Ketersediaan teknologi & 2.67 & 0.056 & 0.150 \\
\hline $\mathrm{H}$ & Persaingan yang sehat dengan kompetitor & 2.67 & 0.061 & 0.162 \\
\hline \multicolumn{5}{|c|}{ ANCAMAN } \\
\hline $\mathrm{I}$ & $\begin{array}{l}\text { Kondisi perekonomian yang terpuruk akibat Covid } \\
-19\end{array}$ & 2.00 & 0.081 & 0.162 \\
\hline $\mathrm{J}$ & $\begin{array}{l}\text { Efek pandemi Covid - } 19 \text { yang membatasi } \\
\text { pergerakan pasar internasional }\end{array}$ & 1.50 & 0.077 & 0.115 \\
\hline K & $\begin{array}{l}\text { Kebijakan impor teh yang mematikan industri teh } \\
\text { nasional secara perlahan }\end{array}$ & 2.17 & 0.092 & 0.199 \\
\hline $\mathrm{L}$ & Masih banyaknya gangguan usaha perkebunan & 1.83 & 0.079 & 0.145 \\
\hline $\mathrm{M}$ & Kondisi iklim dan lingkungan & 2.67 & 0.076 & 0.204 \\
\hline $\mathrm{N}$ & $\begin{array}{l}\text { Edukasi mengenai pentingnya konsumsi teh yang } \\
\text { masih kurang didalam negeri }\end{array}$ & 2.50 & 0.083 & 0.207 \\
\hline \multicolumn{3}{|c|}{ Total } & 1.000 & 2.441 \\
\hline
\end{tabular}

\section{Analisis Matriks IE}

Kombinasi dari hasil Analisis Matriks IFAS dan EFAS menghasilkan Matriks IE yang terdiri dari sembilan sel. Total skor untuk Analisis Matriks IFAS sebesar 2,609 diletakkan pada sumbu X dan total skor untuk Analisis Matriks EFAS sebesar 2,441 diletakkan pada sumbu Y. Matriks IE pada Tabel 6 menempatkan Kebun Kertamanah pada sel V yang menunjukkan strategi pelihara dan pertahankan (hold and mantain). Menurut (David, 2006), perusahaan yang berada pada posisi ini dianjurkan melakukan 
strategi intensif seperti melakukan melakukan strategi penetrasi dan pengembangan pasar, pengembangan produk, serta meningkatkan penerapan teknologi. Sebagai contoh, Kebun Kertamanah saat ini memiliki opsi untuk meningkatkan kembali kuantitas dan kualitas produksi dengan menambah kapasitas olah pabrik dan pembaharuan beberapa mesin pengolahan melalui program Pabrik Unggulan PTPN VIII. Selain itu menurut (Kurniawan et al., 2013), perusahaan yang berada pada sel V dapat memperbesar pangsa pasar baik melalui peningkatan kuantitas maupun kualitas produk, dapat pula meningkatkan fasilitas produksi dan penguasaan teknologi baik melalui pengembangan sumberdaya internal maupun eksternal perusahaan.

Tabel 6.

Matriks Internal - Eksternal (IE) Teh Kebun Kertamanah

\begin{tabular}{ccccc}
\hline \multicolumn{5}{c}{ Total Skor IFAS $=\mathbf{2 , 6 0 9}$} \\
\hline \multirow{4}{*}{$\begin{array}{c}\text { Tinggi } \\
3,0-4,0\end{array}$} & $\begin{array}{c}\text { Rata }- \text { Rata } \\
2,0-2,99\end{array}$ & $\begin{array}{c}\text { Lemah } \\
1,0-1,99\end{array}$ \\
Total & $\begin{array}{c}\text { Tinggi } \\
\text { Skor }\end{array}$ & I & II & III \\
\cline { 2 - 5 } EFAS $=$ & $\begin{array}{c}\text { Rata - Rata } \\
2,0-2,99\end{array}$ & IV & V & VI \\
\cline { 2 - 5 } & $\begin{array}{c}\text { Lemah } \\
1,0-1,99\end{array}$ & VII & VIII & IX \\
\hline
\end{tabular}

\section{Analisis Matriks SWOT}

Analisis matriks SWOT digunakan sebagai alat bantu guna menciptakan berbagai alternatif strategi yang kemudian dapat menjadi referensi bagi perusahaan untuk mengembangkan usahanya. Matriks SWOT pada Tabel 7 dirancang berdarkan analisis lingkungan internal dan eksternal perusahaan.

Tabel 7.

Analisis Matriks SWOT Teh Kebun Kertamanah

\begin{tabular}{|c|c|c|}
\hline INTERNAL & 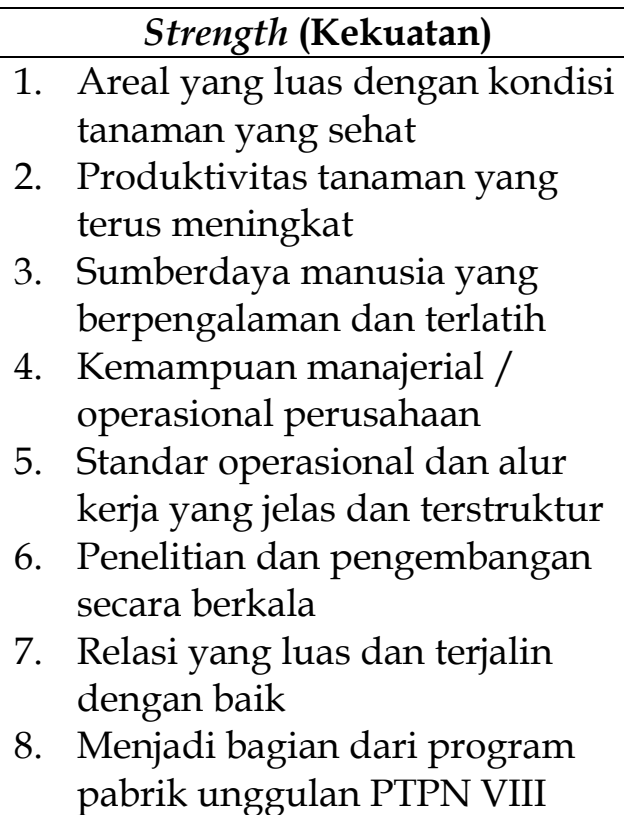 & $\begin{array}{l}\text { Weakness (Kelemahan) } \\
\text { 1. Kapasitas olah } \\
\text { pabrik masih rendah } \\
\text { 2. Mutu produk yang } \\
\text { belum konsisten } \\
\text { 3. Masih adanya hasil } \\
\text { produksi yang } \\
\text { mengendap } \\
\text { 4. Pemasaran dan } \\
\text { promosi yang masih } \\
\text { belum maksimal } \\
\text { 5. Akses jalan produksi } \\
\text { yang kurang baik } \\
\text { 6. Sulitnya memperoleh } \\
\text { mata air di lapangan }\end{array}$ \\
\hline
\end{tabular}




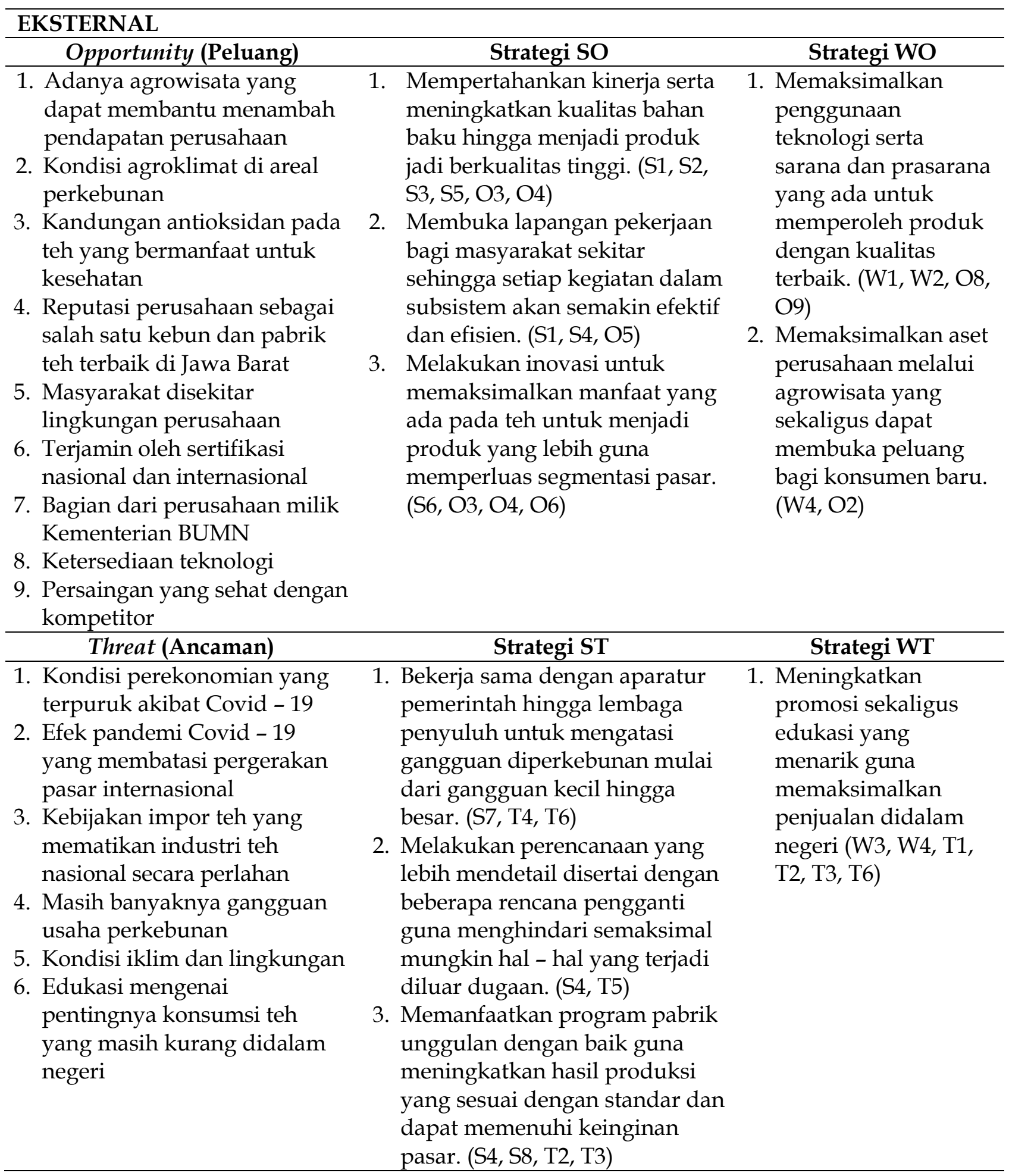

Berdasarkan Analisis Matriks SWOT diperoleh sembilan alternatif strategi yang terdiri dari tiga alternatif S-O, tiga alternatif S-T, dua alternatif $\mathrm{W}-\mathrm{O}$, dan satu alternatif W-T. Guna menentukan strategi yang tepat untuk dilakukan oleh perusahaan sesuai dengan keadaan lingkungan internal dan eksternal perusahaan, maka dilakukan pemetaan total skor matriks internal dan eksternal ke dalam Diagram Cartesius pada Gambar 3. Berdasarkan diagram tersebut terlihat bahwa strategi pengembangan agribisnis teh Kebun Kertamanah berada pada kuadran I yang mendukung strategi agresif atau strategi S-O (Strength - Opportunity) dimana perusahaan memiliki kekuatan sehingga dapat memanfaatkan peluang yang ada. Menurut (Songi et al., 2018), 
kekuatan yang lebih besar dibanding kelemahan serta ancaman yang lebih kecil dibanding peluangnya menjadikan strategi pengembangan perusahaan berada pada kuadran I yang mendukung strategi agresif atau strategi SO (strength - opportunity).

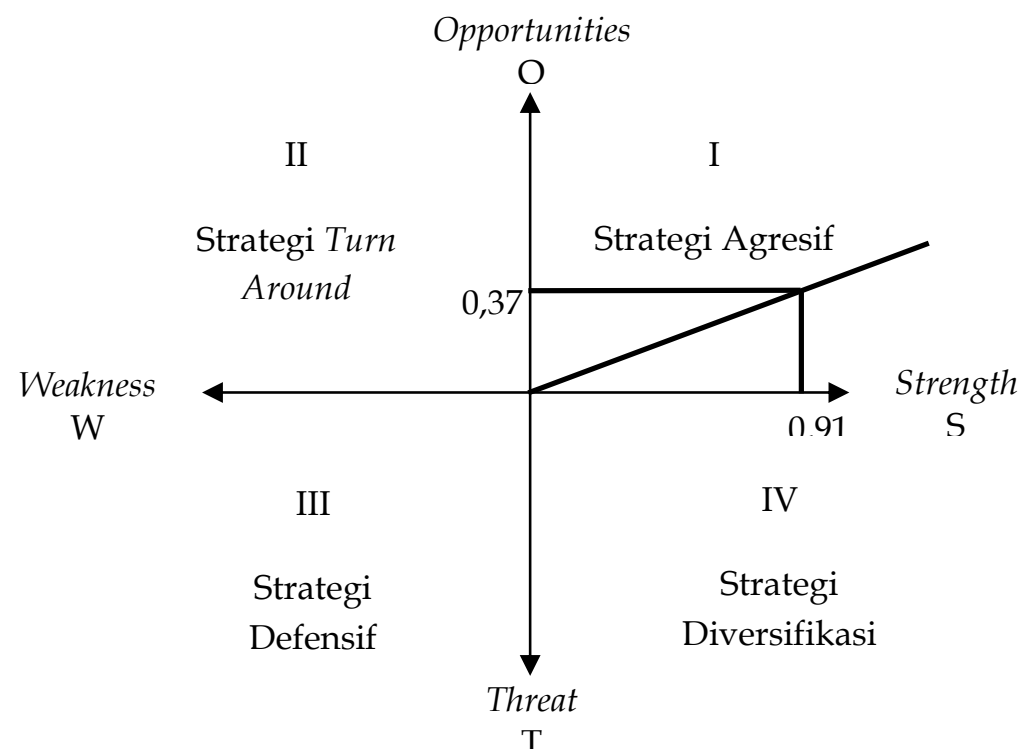

Gambar 3. Diagram Cartesisus Analisis SWOT Kebun Kertamanah

\section{Kesimpulan}

Subsistem pengadaan input produksi mendukung berjalannya subsistem produksi / budidaya dan subsistem pengolahan. Selanjutnya kedua subsistem tersebut mendukung berjalannya kegiatan pada subsistem pemasaran. Perubahan yang cukup terasa selama masa pandemi Covid - 19 terdapat pada subsistem pemasaran karena adanya hambatan dari sisi logistik khususnya untuk pasar ekspor. Matriks IE merekomendasikan strategi intensif sebagai alternatif pilihan strategi yang dapat digunakan perusahaan, yakni dengan melakukan penetrasi pasar dan pengembangan produk. Analisis SWOT menghasilkan sembilan alternatif strategi dan perusahaan dianggap sesuai untuk melakukan strategi agresif. Hal tersebut dapat menjadi referensi dan bahan pertimbangan bagi perusahaan untuk menyusun strategi pengembangan yang tepat guna mengembangkan usahanya berdasarkan hasil analisis mendalam pada faktor internal dan eksternal yang dimiliki oleh perusahaan.

Perusahaan diharapkan dapat menjaga dan meningkatkan kinerja kegiatan agribisnis teh yang saat ini sudah berada pada kondisi yang baik, dengan tetap melakukan pengontrolan serta evaluasi secara berkala guna memastikan tiap subsistem berjalan dengan saling mendukung satu sama lain. Perusahaan pun diharapkan dapat melakukan perencanaan penambahan areal gudang agar beberapa produk yang mengendap dapat tersimpan dengan baik. Guna mengurangi pengendapan produk karena penjualan yang sedikit terhambat karena adanya pandemi Covid - 19, perusahaan diharapkan dapat meningkatkan kembali kegiatan pemasaran dan promosi di dalam negeri serta dapat melakukan perluasan jalinan kemitraan. Setelah diperoleh beberapa rumusan strategi dari penelitian ini, untuk penelitian selanjutnya dapat dikaji secara lebih mendalam mengenai perioritas dari beberapa referensi strategi serta dapat dilakukan pula analisis finansial agar penerapan strategi dapat dilakukan secara efektif dan efisien sesuai dengan kemampuan perusahaan. 


\section{Daftar Pustaka}

Arfah, S. Y. C. (2019). Strategi Pengembangan Agribisnis Kakao Di Sulawesi Tengah. Jurnal Agroland, 26(2), 179-188.

Awaliyah, F. (2018). Keragaan Agribisnis Komoditas Mangga Gedong Gincu Di Kabupaten Cirebon. Jurnal Mahatani, 1(2), 129-141.

Choiri, A., \& Sunartomo, A. F. (2008). Keragaan Agribisnis Dan Prospek Pemasaran Kopi Rakyat. Jurnal Sosial Ekonomi Pertanian (Jsep), 2(3), 13.

Creswell, J. W. (2014). Research Design: Qualitative, Quantitative, And Mixed Method Approaches. Sage.

David, F. R. (2006). Manajemen Strategis. Salemba Empat.

Gumbira-Sa'id, E., \& Intan, A. H. (2001). Manajemen Agribisnis. Ghalia Indonesia.

Karmini. (2020). Dasar - Dasar Agribisnis. Mulawarman University Press.

Kurniawan, M. F. T., Darmawan, D. W. I. P., \& Astiti, N. W. S. R. I. (2013). Strategi Pengembangan Agribisnis Peternakan Ayam Petelur Di Kabupaten Tabanan T. Jurnal Manajemen Agribisnis, 1(2), 53-66.

Prasetya, M. H., Zebua, D. D. N., \& Yuliawati. (2021). Faktor Internal Dan Eksternal Yang Mempengaruhi Tingkat Resistensi Petani Terhadap Usahatani Padi Organik. Jurnal Sosial Ekonomi Pertanian, 17(1), 39-51.

Rahim, A., \& Hastuti, D. R. D. (2005). Sistem Manajemen Agribisnis. Badan Penerbit Universitas Negeri Makassar.

Rangkuti, F. (1997). Analisis Swot: Teknik Membedah Kasus Bisnis. Pt. Gramedia Pustaka Utama.

Ratih, F., Nanda, F., \& Tinaprilla, N. (2012). Analisis Daya Saing Dan Strategi Pengembangan Agribisnis Teh Indonesia. Forum Agribisnis: Agribusiness Forum, 2(1), 33-52.

Silaban, M. G. D. (2020). Strategi Pengembangan Agribisnis Stroberi Pada CV. Bumi Agro Technology, Jawa Barat. Universitas Padjadjaran.

Songi, R. I., Baruwadi, M., \& Rauf, A. (2018). Strategi Pengembangan Agribisnis Bawang Merah Di Kecamatan Paguyaman Kabupaten Boalemo. Agrinesia: Jurnal Ilmiah Agribisnis, 3(1), 30-38.

Sugiyono. (2015). Metode Penelitian Kuantitatif, Kualitatif, Dan RED. Alfabeta.

Suoth, V., Loho, A. E., \& Ruauw, E. (2019). Keragaan Sistem Agribisnis Kakao (Theobroma cacao) Di Kabupaten Bolaang Mongondow Utara. Jurnal AgriSosioekonomi Unsrat, 15(2), 369-376. 